\title{
AC 2009-605: EFFECTIVE: EXPLORING A FRAMEWORK FOR EVALUATING COURSES ON TECHNOLOGY IN VARIOUS ENVIRONMENTS
}

\section{John Krupczak, Hope College}

Senior Fellow, Center for the Advancement of Scholarship on Engineering Education (CASEE)

National Academy of Engineering and Professor of Engineering, Hope College

Timothy Simpson, Pennsylvania State University

Professor of Mechanical and Industrial Engineering and Engineering Design and Director, The Learning Factory, Pennsylvania State University

Vince Bertsch, Santa Rosa Junior College

Professor of Engineering and Physics

Kate Disney, Mission College

Engineering Instructor

Elsa Garmire, Dartmouth College

Member, National Academy of Engineering and Sydney E. Junkins 1887 Professor of Engineering, Dartmouth College 


\title{
EFFECTIVE: Exploring a Framework for Evaluating Courses on Technology In Various Environments
}

\begin{abstract}
There is an urgent need for all Americans to better understand the wide variety of technology used everyday. Technological literacy is important at both an individual and national level. In two reports: Technically Speaking: Why All Americans Need to Know More about Technology (2002), and Tech Tally: Approaches to Assessing Technological Literacy (2006), the National Academy of Engineering (NAE), has outlined the characteristics of a technologically literate citizen. The NAE defines the term technological literacy as an understanding of all types of technology not just computers and information technology. Technological literate citizens have a broad comprehension of the diverse products of all the engineering professions. The International Technology Education Association (ITEA) and the American Association for the Advancement of Science (AAAS) have also produced standards that include an understanding of technology. Creating a population with a more thorough understanding of technology will require an extensive effort by educators at undergraduate institutions. Courses and materials that are easily adoptable in diverse and varied colleges and universities will be needed. Recognizing the need for standardized and readily adoptable undergraduate courses on this topic, the NSF supported a working group lead by the American Society for Engineering Education (ASEE) Technological Literacy Constituent Committee. This group met on March 26-27, 2007 and adopted four models to serve as standardized courses on technology. In this work, a framework for specific course outlines consistent with the content areas established in Tech Tally of: technology and society, design, products and systems, and technology core concepts and the ITEA technology topic areas was created. To help instructors to satisfy the requirements of curriculum committees on varied campuses, the framework offers flexibility in configuring courses within each proposed model while still accomplishing the intent of the standards. This framework will be used in creating a repository of course materials that will be accessible online to assist course developers and instructors. The framework will help faculty develop expertise in adapting existing innovative course materials and standards for defining technological literacy and incorporating them efficiently into their own courses.
\end{abstract}

\section{Background}

Technology affects nearly every aspect of our lives, and informed citizens need an understanding of what technology is, how it works, how it is created, how it shapes society, and how society influences technological development. How well American citizens understand these issues depends in large part on their level of technological literacy.

In their 2006 report, Tech Tally [3], the NAE defined technological literacy as "an understanding of technology at a level that enables effective functioning in a modern technological society". Tech Tally was a follow-up to a 2002 report by the NAE entitled, Technically Speaking: Why All Americans Need to Know More about Technology, which describes the importance of being knowledgeable about technology in the $21^{\text {st }}$ century [4]. Both NAE reports define technology, in a broad sense, as any modification of the natural world made to fulfill human needs and wants. 
This includes not only its tangible products, but also the knowledge and processes necessary to create and operate those products. The infrastructure used for the design, manufacture, operation, and repair of technological artifacts is also considered part of technology, in its broadest sense.

Other efforts have sought to develop standards to define what K-12 students need to know and be able to do concerning technology. In 1993, the American Association for the Advancement of Science (AAAS) published, Project 2061: Benchmarks for Science Literacy [5] and in 1996 the National Science Education Standards were published by the National Academies Press [6], both of these included standards devoted to technology. In 2000 the International Technology Education Association (ITEA) published Standards for Technological Literacy: Content for the Study of Technology [7]. This effort was directed toward developing educational curricula that would address the technological literacy of K-12 students

In defining technological literacy in Technically Speaking, the NAE identified three major dimensions or components related to technological literacy: knowledge, capabilities, and ways of thinking and acting. These concepts were defined in more detail in Tech Tally. As defined in this report, "The 'knowledge dimension' of technological literacy includes both factual knowledge and conceptual understanding. The 'capabilities dimension' relates to how well a person can use technology (defined in its broadest sense) and carry out a design process to solve a problem." The final dimension 'ways of thinking and acting' was rephrased as a 'critical thinking and decision-making' dimension. This has to do with and individual's approach to technological issues. This dimension enables the individual to ask questions about risks and benefits when introduced to a new technology, and to participate in discussions and debates about the uses of that technology.

In addition to these three cognitive dimensions, The NAE defined four content areas: (1) technology and society, (2) design, (3) products and systems, and (4) characteristics, concepts, and connections. Finally, an assessment matrix was proposed that combined the four content areas with the three cognitive dimensions. This matrix is shown in Figure 1 which is adapted from Figure ES-2 from Tech Tally.

The International Technology Education Association (ITEA) also developed a set of standards, which was published in a report entitled, Standards for Technological Literacy: Content for the Study of Technology [7]. The ITEA 2000 Standards are divided into five main categories that sub-divide into 20 specific standards. Table 1 summarizes the 20 specific areas addressed by the ITEA standards. While the ITEA 2000 standards address K-12 students, the detail of these standards is useful in categorizing or classifying content areas that might appear in technological literacy courses for undergraduates. 


\section{COGNITIVE DIMENSIONS}

\begin{tabular}{|c|l|l|l|}
\hline & Knowledge & Capabilities & $\begin{array}{l}\text { Critical Thinking \& } \\
\text { Decision Making }\end{array}$ \\
\hline $\begin{array}{c}\text { Technology \& } \\
\text { Society }\end{array}$ & & & \\
\hline Design & & & \\
\hline $\begin{array}{c}\text { Products \& } \\
\text { Systems }\end{array}$ & & & \\
\hline $\begin{array}{c}\text { Characteristics, } \\
\text { Core Concepts, } \\
\text { \& Connections }\end{array}$ & & & \\
\hline
\end{tabular}

Figure 1: Proposed assessment matrix for technological literacy in Tech Tally.

Table 1: Listing of the ITEA Technological Literacy Standards.

\begin{tabular}{|rl|}
\hline 1 & The Nature of Technology \\
2 & The core concepts of technology. \\
3 & The relationships among technologies and the connections between \\
& technology and other fields. \\
& Technology and Society \\
4 & The cultural, social, economics, and political effects of technology. \\
5 & The effects of technology on the environment. \\
6 & The role of society in the development and use of technology. \\
7 & The influence of technology on history. \\
& Design \\
8 & The attributes of design. \\
9 & Engineering design. \\
10 & The role of troubleshooting, research and development, invention and \\
& innovation, and experimentation and problem solving. \\
& Abilities for a Technological World \\
11 & Apply the design process. \\
12 & Use and maintain technological products and systems. \\
13 & Assess the impact of products and systems. \\
& The Designed World \\
14 & Medical technologies \\
15 & Agricultural and related biotechnologies. \\
16 & Energy and power technologies. \\
17 & Information and communication technologies. \\
18 & Transportation technologies. \\
19 & Manufacturing technologies. \\
20 & Construction technologies. \\
\hline
\end{tabular}




\section{Development of Model Courses}

At a recent NSF workshop participants sought to create a set of standard models for teaching technological literacy courses [1,2]. As part of that workshop, a collection of technological literacy courses already developed by engineers was identified. The course instructors or developers of 22 courses were surveyed to determine the extent to which these existing courses included the definitions of technological literacy as defined by both the NAE and ITEA standards [8]. The survey results are summarized in Figures 2 and 3.

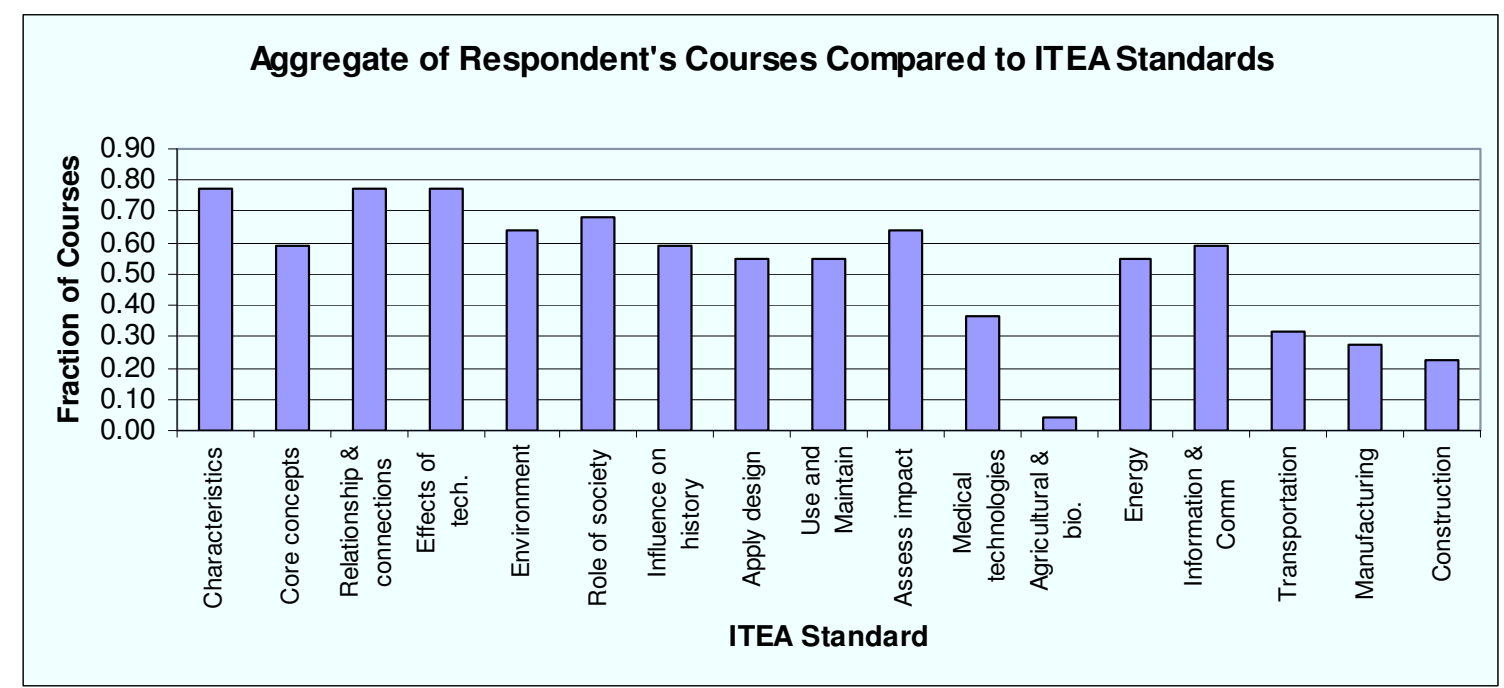

Figure 2. Aggregate of Respondent's Courses Compared to ITEA Standards

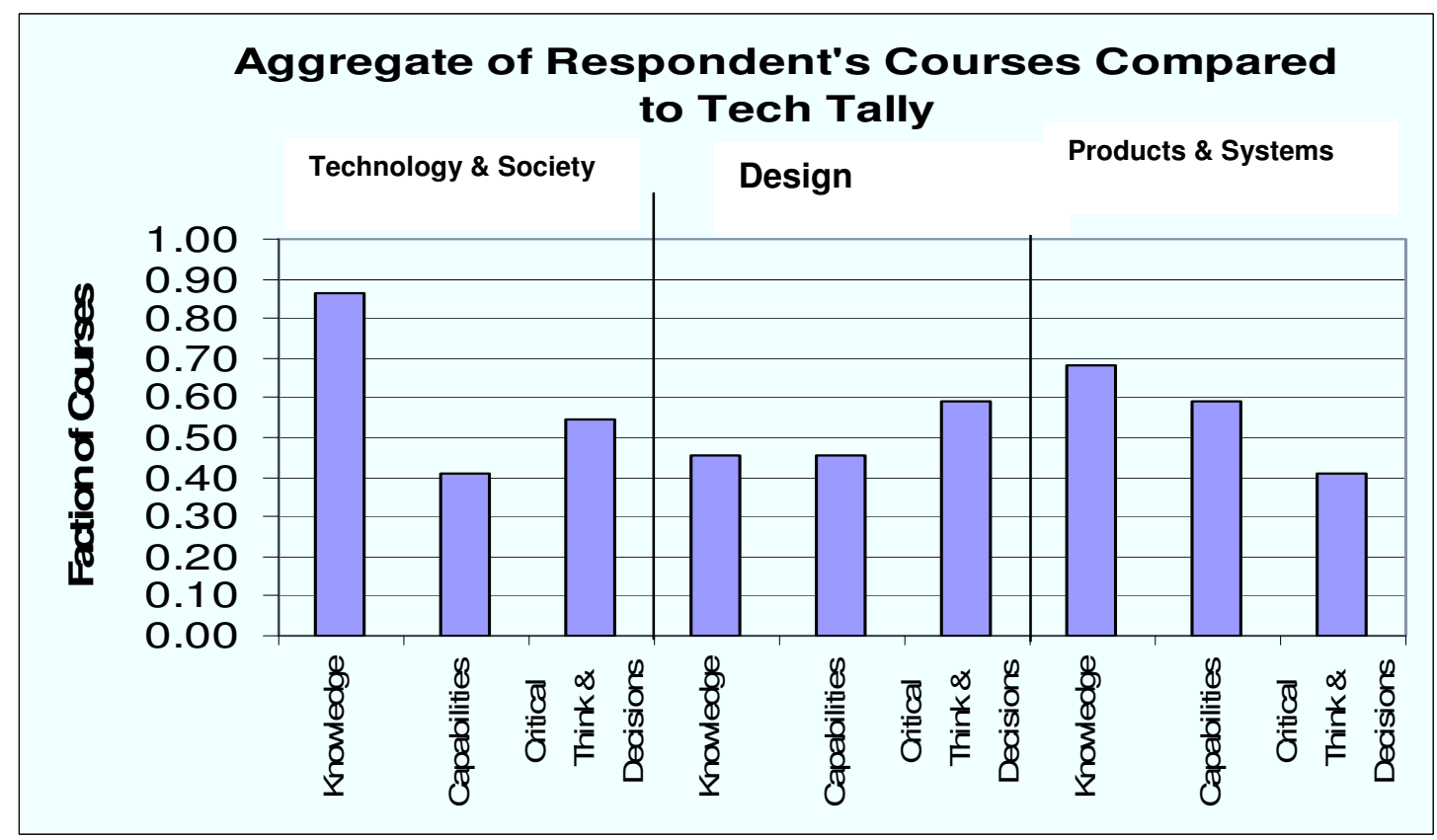

Figure 3: Aggregate of Respondent's Courses Compared to NAE Tech Tally Standards. 
These survey results shown in Figures 2 and 3 are encouraging in indicating that the existing courses are addressing a significant amount of the material specified in both the NAE and ITEA standards. Figure 2 shows that about 40 percent of all of the courses surveyed included most of the ITEA content areas. The one major exception is the content area of agricultural and biotechnology which was included in less than 10 percent of all existing courses. Figure 3 shows that about 40 percent of all courses included material on Technology and Society, Design, and Technological Products and Systems, at the level of thinking and decision making as defined in Tech Tally.

A conclusion from this portion of the work is that there are at least some already existing course materials developed by engineering faculty that are sufficient to address all of the ITEA and NAE standards. However the materials are dispersed through the 22 courses surveyed. One way to view this is that it is possible for a non-engineering student to take already existing courses and obtain technological literacy as defined by the NAE and ITEA, however it would require taking a significant fraction of the 22 courses to achieve this outcome. A more efficient organization of courses is needed.

The existing courses were reviewed to determine if some classification or organizational theme could be identified. Based on a review of courses already developed and comparisons to other disciplines, four standard models were identified:

- The Technology Survey Course.

- The Technology Focus or Topics Course.

- The Technology Creation Course (Design Course).

- The Technology Critique, Assess, Reflect, or Connect Course.

The technology survey courses offer a broad overview of a number of areas of engineering and technology. The technology or topics or focus course is narrower in scope and develops one well-defined area. The engineering design course, or technology creation course, places an emphasis on the engineering design process to develop technological solutions to problems. The last model to emerge is concerned with assessing technological impacts, connecting technological developments to other areas of society, history and culture, or reflecting on engineering in a broader context. A schematic representation of the four course models is shown in Figure 4.

Most of the existing technological literacy courses were established before the recent efforts by the NAE and the ITEA to define technological literacy and establish standards for this topic. Individual instructors determined course syllabi based on their expertise and level of comfort with the material. While it was found that elements of the NAE and ITEA standards had been incorporated into most of the existing courses, no single existing course included all of the standards due to their breadth. With this came the realization that while no single standard course model could be developed for a course on technological literacy, the four standard course models may offer a means to systematically address the NAE and ITEA standards. 


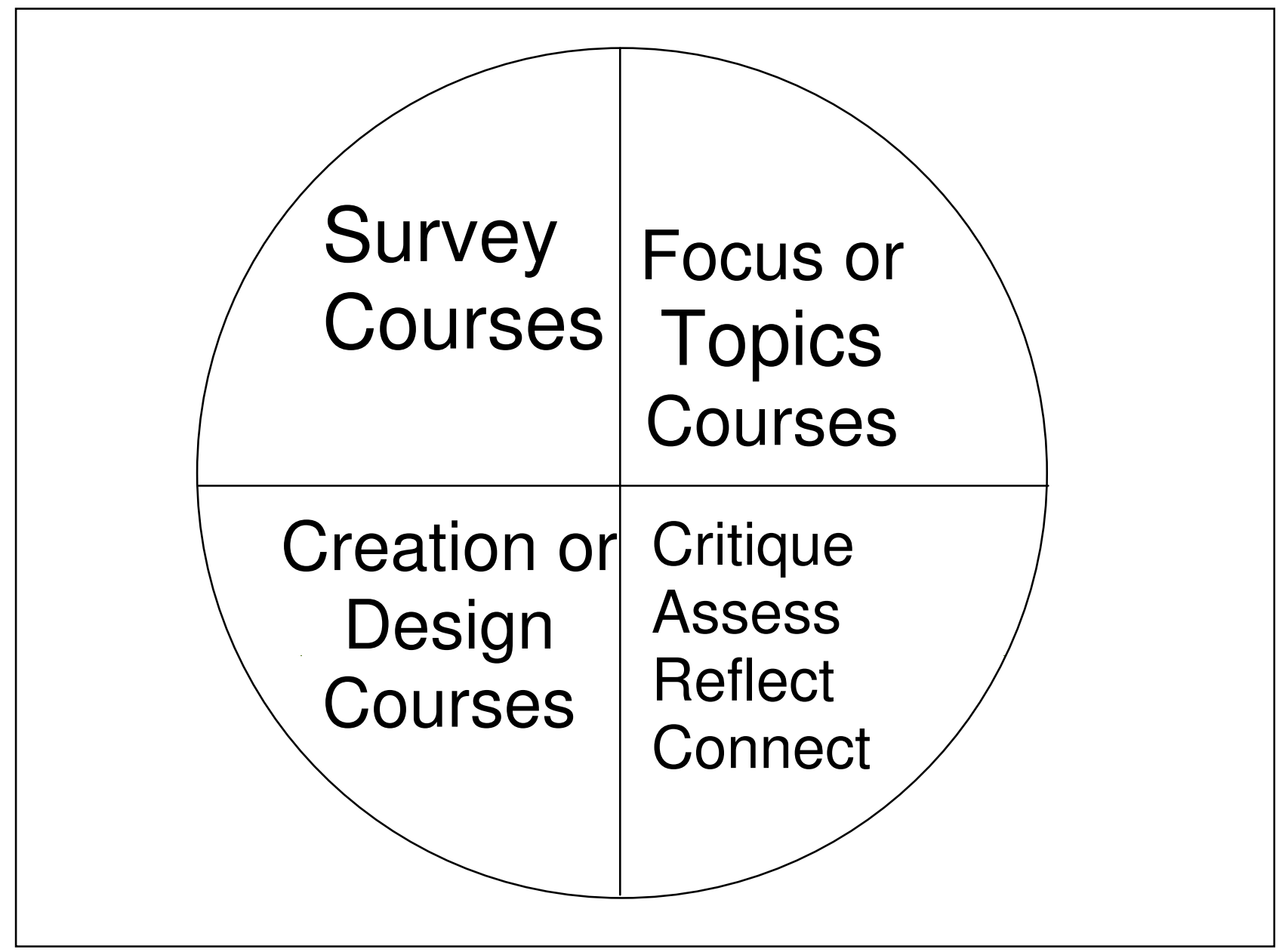

Figure 4: A Schematic Representation of Four Distinct Types of Technological Literacy Courses.

\section{Description of the EFFECTIVE Course Development Framework}

A proposed framework for course organization was developed by a team at the 2007 NSF/NAE Workshop on Technological Literary of Undergraduates [9]. The framework is currently embodied in the form of a 2D matrix that maps content areas - called cross-cutting concepts - to different technology topic areas, as shown in Figure 5. The technology topic areas - the columns in the matrix - are derived from the "Designed World" categories defined by the ITEA 2000 Standards [7] and include an additional "Other" category for areas that the workshop participants found were missing from ITEA's Designed World based on the existing course contents. 


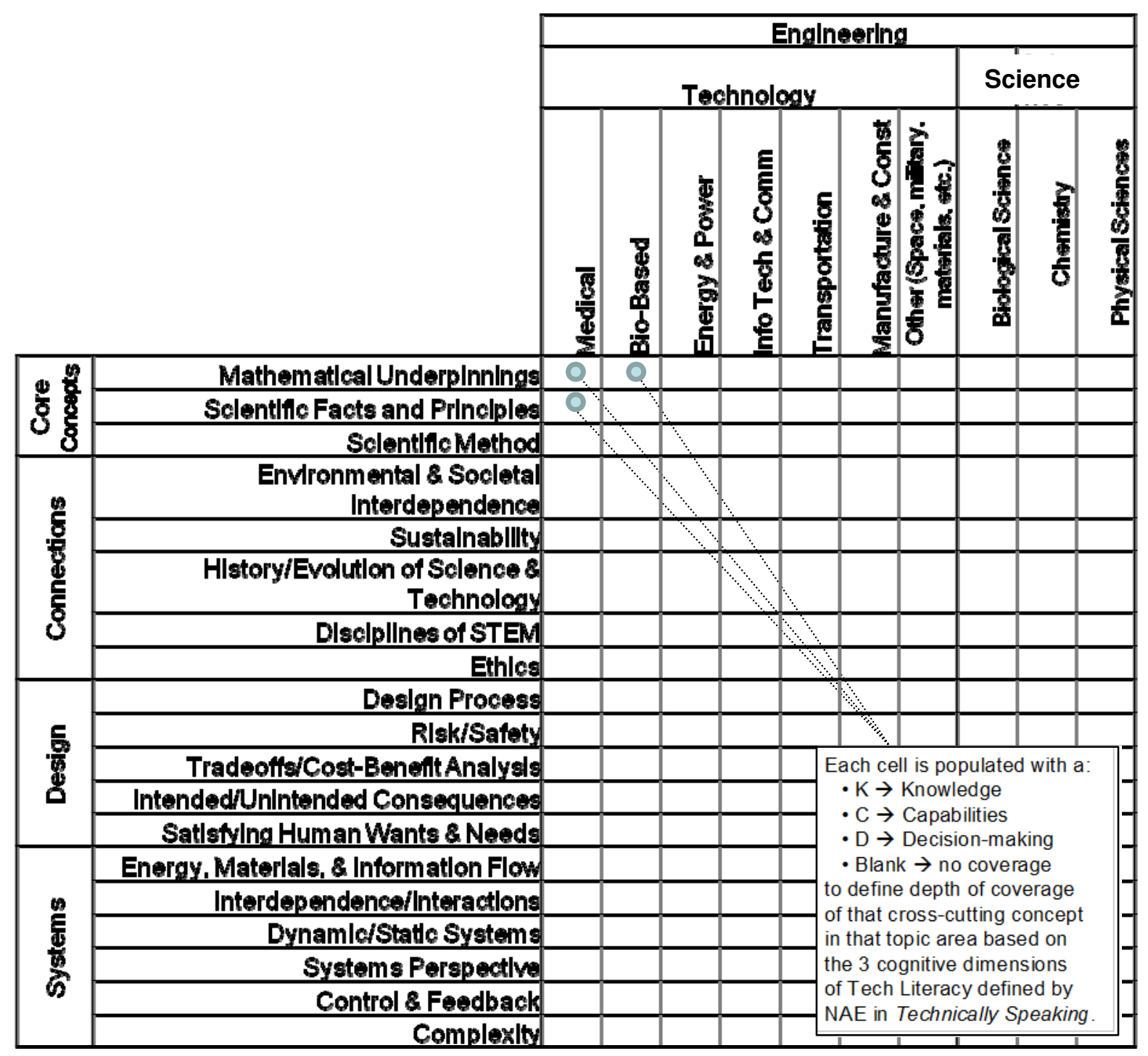

Figure 5: EFFECITVE Technological Literacy Course Development Framework.

The rows of the matrix in Figure 5 are specific cross-cutting concepts grouped under the broader headings of Systems, Design, and Connections, and Core Concepts which are based on the four content areas defined in Tech Tally [3]: (i) Technology \& Society, (ii) Design, (iii) Products \& Systems, and (iv) Characteristics, Core Concepts, \& Connections.

Each cell in the matrix can now be populated with one of four values as noted in Figure 5 to indicate the depth of coverage of that cross-cutting concept in each technology topic area:

1. $\mathrm{K} \rightarrow$ Knowledge, i.e., the course will provide knowledge about this cross-cutting concept within the context of this technology topic area

2. $\mathrm{C} \rightarrow$ Capabilities, i.e., the course will develop capabilities in this cross-cutting concept that can be applied within the context of this technology topic area 
3. $\mathrm{D} \rightarrow$ Decision-making, i.e., the course will enable decision-making within the context of this cross-cutting with regards to this technology topic area

4. Blank - Indicates that this cross-cutting concept is not covered to any extent within this technology topic area

These three areas (K, C, D) are based on the three Cognitive Dimensions of Technology Literacy that are defined in Technically Speaking [5] and Tech Tally [3] where "Critical Thinking \& Decision-making" has been simplified to "Decision-making". The levels (K, C, D) are ordered in terms of their depth of understanding. This is consistent with the scheme used in Bloom's taxonomy.

Using this 2D matrix representation, the four generic types of technology literacy courses can be defined [9]. These are shown in Figure 6. To simplify the figures, the cross-cutting concepts along the rows have been condensed into the three groups. As shown in the figure, it is expected that survey courses will span the majority of the matrix. Due to time constraints and limited course duration, it is not anticipated that any survey course will fill the entire matrix completely. However, it is expected that no row would be completely blank. A column could be blank if a technology topic area is not covered due to time limits, but a survey course will likely cover most of these technology areas.

Technological literacy focus courses will go into significant depth within one or more technology topic areas, as shown Figure $6 \mathrm{~b}$, with a higher percentage of $\mathrm{C}$ and $\mathrm{D}$ values in that column(s) when compared to a survey course.

Technological Literacy Design Courses and Critique, Assess, Reflect, or Connect (CARC) Courses will cover these respective rows in the matrix for one or more of the technology topic areas as shown in Figures $6 \mathrm{c}$ and $6 \mathrm{~d}$, respectively. It is expected that these courses will also have a higher percentage of $\mathrm{C}$ and $\mathrm{D}$ values in the corresponding rows - specifically for the detailed cross-cutting concepts within each group - compared to a survey course.

\section{Description of Current Work}

The framework shown in Figure 5 will serve as an organizational infrastructure for a web-based repository of shared course materials. This online matrix will contain links to course materials from existing technological literacy courses. This will allow faculty users to build technological literacy courses by selecting appropriate materials from cells, rows, or columns as needed. Faculty will be able to submit modules or full course materials. The advantage of this approach is found in the use of one common matrix familiar to all instructors that reflects the NAE and ITEA standards. Users will be able to view individual course matrices or review materials available along one dimension (row or column) of the common matrix. Materials will also indicate cognitive level K, C, and D addressed. 


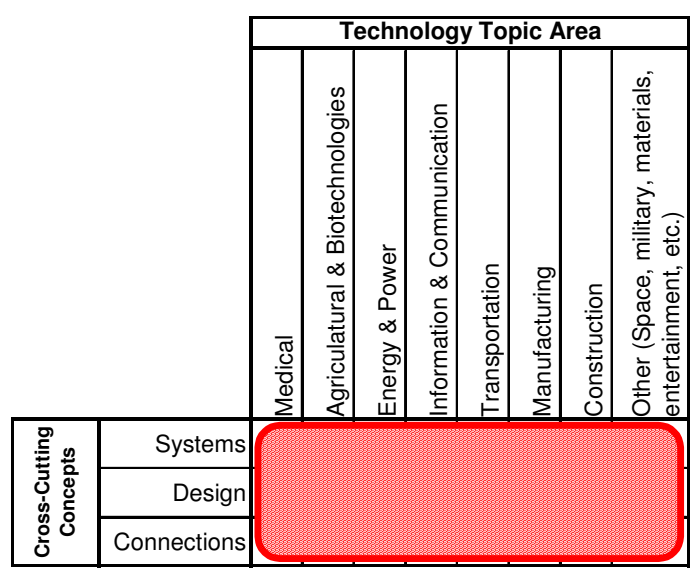

(a) Technology Survey Courses

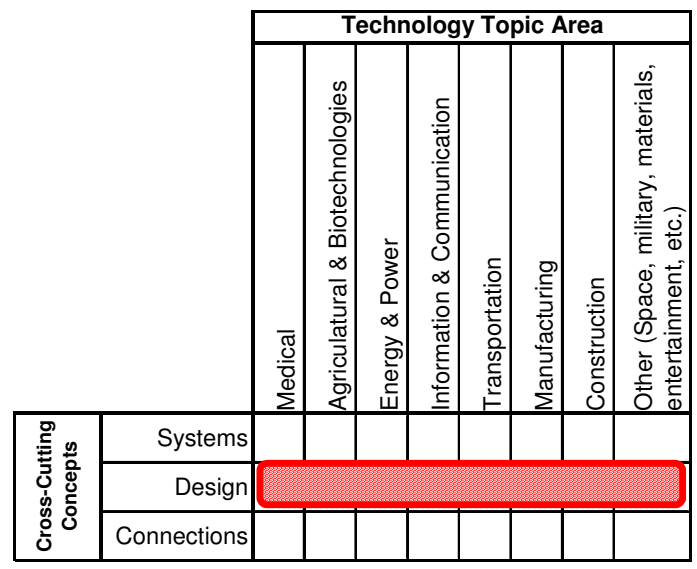

(c) Technology Design Courses

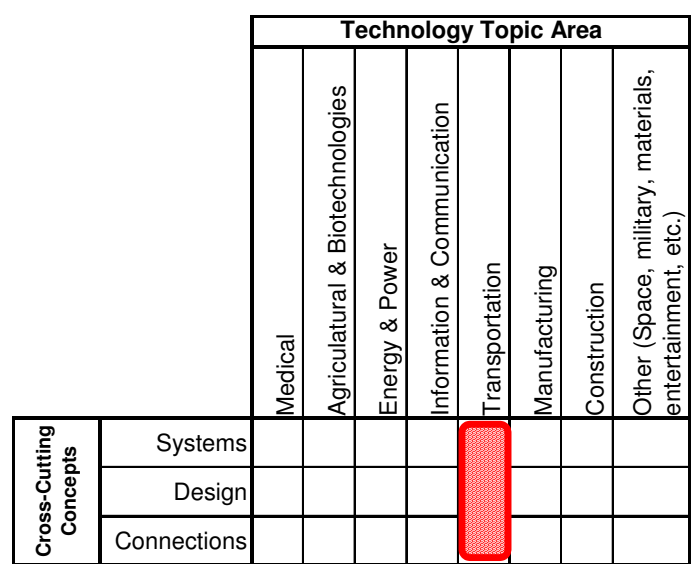

(b) Technology Focus Courses

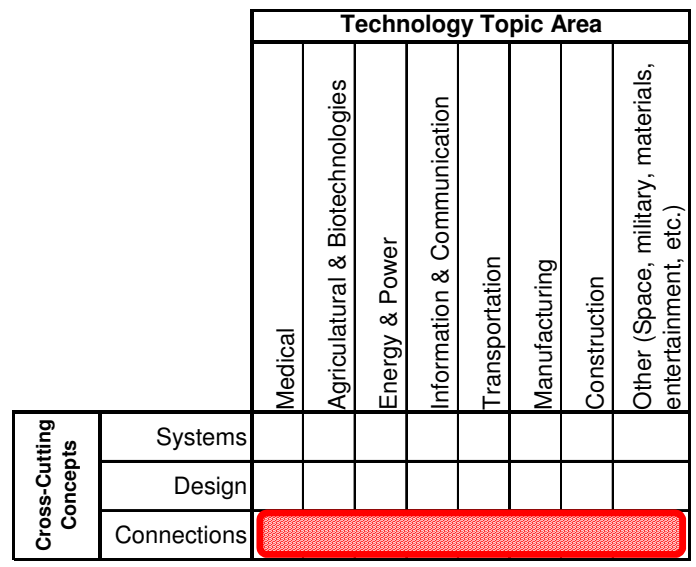

(d) Technology Critique/Assess/Reflect/Connect Courses

Figure 6. EFFECTIVE Framework Defining Four Types of Courses for Non-Engineers [9].

The long-range goal of this work is to have the framework serve as a means to develop a community of educators addressing technological literacy. The overarching goal is to make it easier to develop new courses and to find faculty with similar interests. It is anticipated that the creation of a wiki-like environment of best-practice materials will help broaden participation in this area.

\section{Acknowledgement}

The work was supported by the National Science Foundation under award: DUE-0714137 and DUE-0736615. Any opinions, findings, and conclusions or recommendations expressed in this material are those of the authors and do not necessarily reflect the views of the National Science Foundation. 


\section{Bibliography}

1. Technological Literacy of Undergraduates: Developing Standard Models, A Workshop at the National Academy of Engineering, March 27-28, 2007. http://www.nsf.gov/events/event_summ.jsp?cntn_id=108527\&org=NSF http://www.nsf.gov/attachments/108527/public/Tech_Lit_Workshop_Background.pdf.

2. Krupczak, J.J., D. Ollis, W. B. Carlson, K.Neeley, R. Pimmel, and G. Pearson, "The Technological Literacy of Undergraduates: Developing Standard Models," Proceedings of the 37th ASEE/IEEE Frontiers in Education Conference, (2007).

3. Tech Tally: Approaches to Assessing Technological Literacy, Elsa Garmire and Greg Pearson, editors, National Academies Press, (2002).

4. Technically speaking: Why all Americans need to know more about technology, Greg Pearson and A. Thomas Young, editors, National Academies Press, (2002).

5. Project 2061: Benchmarks for Science Literacy, American Association for the Advancement of Science, Oxford University Press, (1993).

6. National Science Education Standards, National Research Council, National Academies Press, (1996).

7. International Technology Education Association. Standards for Technological Literacy, International Technology Education Association, Reston, VA (2000).

$<$ http://www.iteaconnect.org/TAA/Publications/TAA_Publications.html $>$.

8. Krupczak, J.J., D. Ollis, “Technology Courses for Undergraduates: Developing Standard Models,” Proceedings of the American Society for Engineering Education Annual Conference, June 22 - 25, 2008, Pittsburgh, PA.

9. Krupczak, J.J, T. Simpson, V.Bertsch, K. Disney, E. Garmire, B. Oakley, M. Rose, “A Framework for Developing Courses on Engineering and Technology for Non-Engineers, "Proceedings of the American Society for Engineering Education Annual Conference, June 22 - 25, 2008, Pittsburgh, PA. 